\title{
Paediatric bone marrow transplantation using donors other than HLA genotypically identical siblings
}

\author{
J M Hows
}

Allogeneic bone marrow transplantation using HLA genotypically identical sibling donors (ID-BMT) is generally accepted as curative treatment for a range of life threatening disorders of childhood affecting the pluripotent haemopoietic stem cell or its progeny. Disorders universally considered suitable for treatment by ID-BMT are those in which the probability of long term survival with a good quality of life is remote if alternative treatment is given. Uncontroversial indications for IDBMT in childhood include severe aplastic anaemia, ${ }^{1}$ severe combined immune deficiency, ${ }^{2}$ and chronic myeloid leukaemia. ${ }^{3}$ In strong contrast, there is little agreement among paediatric haematologists about whether IDBMT should be used as definitive treatment for children with acute leukaemia with no particular risk factors. ${ }^{4}$ Between these two extremes lie several disorders, including thalassaemia major, ${ }^{5}$ in which an increasing number of paediatric haematologists are becoming more enthusiastic about including ID-BMT in their treatment protocols. Some principle indications for transplantation from an HLA identical sibling in childhood are shown in the table.

An important reason for the rising popularity of ID-BMT is the development of myeloablative regimens that exclude the use of total body irradiation. The most successful chemotherapy protocol is high dose busulphan combined with high dose cyclophosphamide. ${ }^{6}$ Preliminary data from the Pesaro group on the long term follow up of patients who underwent bone marrow transplantation for $\beta$ thalassaemia major suggest that busulphan and cyclophosphamide do not

Some major indications for bone marrow transplantation from an HLA identical sibling in childhood

\begin{tabular}{|c|c|}
\hline Disorder & $\begin{array}{l}\text { Optimal timing for bone } \\
\text { marrow transplant }\end{array}$ \\
\hline $\begin{array}{l}\text { No controversy } \\
\text { Severe aplastic anaemia } \\
\text { Fanconi's anaemia } \\
\text { Congenital immunodeficiencies } \\
\text { Chronic myeloid leukaemia }\end{array}$ & $\begin{array}{l}\text { Before multiple transfusions } \\
\text { Before multiple transfusions } \\
\text { Before major infection } \\
\text { First chronic phase }\end{array}$ \\
\hline $\begin{array}{l}\text { Some controversy } \\
\text { Poor risk acute leukaemias } \\
\text { Thalassaemia major } \\
\text { Congenital cytopenias } \\
\text { Inborn errors of metabolism }\end{array}$ & $\begin{array}{l}\text { First or second remission } \\
\text { Before secondary organ damage } \\
\text { Before multiple transfusions } \\
\text { Before secondary organ damage }\end{array}$ \\
\hline $\begin{array}{l}\text { Major controversy } \\
\text { Standard risk acute leukaemia } \\
\text { Sickle cell anaemia }\end{array}$ & $\begin{array}{l}\text { Second remission } \\
\text { Before secondary organ damage }\end{array}$ \\
\hline
\end{tabular}

result in the failure of growth and development seen in young children who underwent transplantation and total body irradiation. ${ }^{7}$ Despite these encouraging data it is almost certain that the vast majority of children who receive transplants and are treated with busulphan and cyclophosphamide will be as infertile as the recipients of total body irradiation.

For most disorders it is generally agreed that ID-BMT should be carried out early before major complications occur and before malignant disorders become resistant to chemotherapy or irradiation. ${ }^{8}$ Exceptions to this rule in childhood are acute lymphoblastic and acute myeloblastic leukaemias with no particular risk factors in which there is a good chance that the child will be cured by chemotherapy alone. ${ }^{4}$ IDBMT is usually reserved for patients in their second remission. Single centre studies and analysis of large data bases held by the European Bone Marrow Transplant Group and the International Bone Marrow Transplant Registry indicate that roughly $70 \%$ of patients with bone marrow failure with no particular risk factors and half of those with leukaemia become long term disease free survivors with a good quality of life after ID-BMT. ${ }^{13}$

The purpose of this review is to discuss the place of bone marrow transplantation in the treatment of children with haematological malignancies and bone marrow failure who lack a HLA identical sibling. Little data have been published on alternative donor bone marrow transplantation in childhood, and it is therefore difficult to make general recommendations. Some principles of donor and patient selection will be discussed, however, which may be helpful to those paediatricians who are considering alternative donor transplantation for children under their care. Formal clinical guidelines can only be established from the results of large prospective studies, such as the International Marrow Unrelated Search and Transplant (IMUST) Study which is currently in progress. ${ }^{9}$

Partially HLA matched family donor bone marrow transplantation LEUKAEMIA

At present the size of families in Western Europe and North America dictates that only $30-35 \%$ of patients have a HLA identical sibling. The Seattle group has pioneered the use of 
partially matched family donor transplants as treatment for leukaemia. Results of their studies strongly suggest that HLA mismatch is only acceptable at the one antigen level. ${ }^{10}$ In this study they showed that patients who received transplants from donors mismatched for two or more HLA antigens had an unacceptably high probability of graft failure, ${ }^{11}$ or severe graft versus host disease. ${ }^{10}$ As a result of this report family members who are phenotypically matched for HLA or are only mismatched by one HLA-A,B, or DR antigen with the patient are often considered suitable donors for patients with haematological cancers. If a phenotypically HLA matched, or one antigen mismatched, family member is available then the clinical indications for bone marrow transplantation are the same as for ID-BMT.

\section{SEVERE APLASTIC ANAEMIA}

It is less certain whether a family donor mismatched for one antigen should be used to give a transplant to a patient with severe aplastic anaemia. Most of the results published so far for partially matched donor bone marrow transplantation for this disease have been disappointing, with graft failure a frequent cause of death probably because of the large proportion of highly sensitised patients who receive transplants. ${ }^{12} 13$ There was also an initial lack of appreciation that more intensive immunosuppressive protocols are required to achieve stable engraftment after partially matched family donor bone marrow transplantation than are needed in ID-BMT for severe aplastic anaemia. In a recent preliminary study Camitta et al used an intensive immunosuppressive protocol including total body irradiation and anti- $T$ cell monoclonal antibody purging of donor marrow for prevention of graft versus host disease. ${ }^{14}$ Results have so far been encouraging with more than half a small number of patients becoming long term survivors.

\section{CONGENITAL IMMUNE DEFICIENCIES AND OSTEOPETROSIS}

This is one area in paediatric bone marrow transplantation where the use of one haplotype (3 antigen) mismatched donors has been successful. In a European collaborative study Fischer et al reported long term actuarial disease free survival of $57 \%$ of patients with congenital immunodeficiencies using HLA haplomismatched family donors, mostly parents. ${ }^{2}$ The success of these transplants was dependent on the use of intensive pretransplant immuosuppressive treatment to prevent graft failure, and $T$ cell purging of the donor marrow to prevent graft versus host disease.

Limitations of mismatched family donor bone marrow transplantation

The main limitation of using HLA mismatched family members as alternative marrow donors is that (apart from in the congenital immunodeficiencies) the procedure is limited to donor recipient pairs with one HLA-A,B, or DR antigen mismatch by graft failure and graft versus host disease. This means that acceptable partially HLA matched donors only extend the famliy donor pool provided by HLA identical siblings by about $10 \%$, leaving about $60 \%$ of potential recipients without a donor.

In certain circumstances an extended family donor search is worthwhile, although it is wise to consult an immunogeneticist before proceeding. Patients whose parents are first cousins may have a HLA phenotypically matched donor in their extended family. In other families in which both maternal and paternal relatives share one common HLA haplotype with the patient, there is a chance of finding a phenotypically matched relative. Extended family donor searches are most important for non-white patients because as will be seen later they have little chance of an HLA 'matched' unrelated donor.

HLA 'matched' unrelated volunteer donors In the early 1970s the Anthony Nolan panel of HLA typed volunteer donors was set up as a collaborative effort between Mrs Shirley Nolan and Dr David James in the department of immunology, Westminster Hospital, London. Initially the panel's aim was to find a marrow donor for Mrs Nolan's son, Anthony, who had Wiskott Aldridge syndrome. After Anthony's death the panel was used to search for donors for patients with a wide range of diseases requiring treatment by bone marrow transplantation. ${ }^{15}$ During the last five years several additional panels of unrelated donors have been set up in different European countries and in the United States and Canada. In the United Kingdom a second panel has been established at the United Kingdom Transplant Service in Bristol, and is made up of National Blood Transfusion Service donors. World wide roughly 300000 HLA typed volunteers are available.

The selection of unrelated donors is at present complicated, time consuming, and expensive. Problem areas can be defined as follows:

(i) Which patients should be selected for unrelated donor searches?

(ii) How can unrelated donors be found for patients from ethnic minorities who often have different HLA phenotypes from the volunteer donors who are predominantly white?

(iii) Which HLA typing and matching tests are best for selecting unrelated donors?

(iv) How can the logistic problems of locating potential donors and obtaining and transporting blood samples for HLA matching be solved?

Patient selection for unrelated donor searches EARLY REFERRAL

$A$ recent analysis of unrelated donor searches done through the two registries in the United Kingdom, and entered into the IMUST study, showed a significantly increased risk of failure because of deterioration or death of the patient when searches were carried out for patients with 
advanced disease. ${ }^{16}$ This is understandable as at present the median time taken for a donor search in the United Kingdom is six months. ${ }^{17}$ At present therefore it is essential to consider the possibility of unrelated donor bone marrow transplantation (UD-BMT) as soon as possible after diagnosis, and to request a search if indicated.

CHRONIC MYELOID LEUKAEMIA

A recent retrospectively analysed study of UDBMT in the United Kingdom showed that a predominantly adult group of patients with chronic myeloid leukaemia in the chronic phase survived longer after UD-BMT than patients with other disorders. ${ }^{18}$ This finding is probably partly because the relatively long chronic phase characteristic of this disorder allows time for an unrelated donor search to be completed before the patient's condition deteriorates. At the Hammersmith Hospital the first 34 adult UDBMT transplants carried out for chronic myeloid leukaemia gave similar results to IDBMT for chronic myeloid leukaemia carried out over the same period of time. Chronic myeloid leukaemia is an unusual leukaemia in the paediatric age group, but when a child does present with it and without a suitable family donor, UD-BMT should be considered.

\section{ACUTE LEUKAEMIA}

Children with acute leukaemia and poor risk features at diagnosis are suitable candidates for early unrelated donor searches. As yet there is no consensus about whether UD-BMT should be carried out during the first or second remission. In one study 39 children received transplants for acute or choronic leukaemia from donors other than HLA identical siblings. Where an unrelated donor was available the patient was randomised to receive either an UD-BMT or a haplomismatched family donor transplant. Twenty six of the patients received transplants for acute leukaemia in their second or a subsequent remission. All children received intensive conditioning treatment before the transplant, and $\mathrm{T}$ cell depleted donor marrow as prophylaxis against graft versus host disease. The length of follow up since the transplant at the time of writing is short, but the projected survival of patients receiving both mismatched family and unrelated grafts two years after bone marrow transplantation was $40-50 \% .{ }^{19}$ At present most paediatric haemotologists are reluctant to treat patients with acute leukaemia with no particular risk factors with UD-BMT in their first remission because of the relatively good prognosis with chemotherapy alone, or chemotherapy together with an autograft.

\section{SEVERE APLASTIC ANAEMIA}

Children with severe aplastic anaemia have a poor outlook if treated with immunosuppressive treatment, especially those children who present under the age of 5 , with a neutrophil count before treatment of $<0.2 \times 10^{9} / 1^{20}$ It is this severely aplastic group of children who should benefit most from UD-BMT, but at the same time they tolerate the wait for an unrelated donor badly. Often the unrelated donor registries will 'fast lane' a search for a severely aplastic child, with excellent results providing the child does not have an unusual HLA phenotype that slows down the search (J Cornish, personal communication). Results of UD-BMT for severe aplastic anaemia have been poor probably because of the high proportion of sensitised patients with advanced disease who were given transplants. ${ }^{12}$ More recently, better results have been documented in a small number of patients who received transplants after an intensive bone marrow transplantation conditioning regimen and $T$ cell depleted donor marrow. ${ }^{14}$

\section{OTHER DISORDERS}

At present most paediatric haematologists are reluctant to treat thalassaemia major by UDBMT because of the relative success of alternative treatments and the increased risk of severe graft versus host disease currently associated with UD-BMT. ${ }^{21}$ Another well defined group of children not often considered for UD-BMT are those with congenital immune deficiencies. This is because of the relative success of haplomismatched family donor bone marrow transplantation. The use of family donors has the additional advantage that there is no delay in finding a donor and bone marrow transplantation can be carried out before the child develops overwhelming infection.

The probability of finding a 'matched' unrelated donor

EFFECT OF SIZE OF DONOR POOL

Bradley estimated the probability of finding a HLA-A,B, DR matched, mixed lymphocyte reaction negative donor from different sizes of donor pools. ${ }^{22}$ Computer simulated searches were based on the HLA phenotypes found in over 1000 randomly selected kidney donors in the United Kingdom. This pool of HLA phenotypes were used to simulate UD-BMT donor panels of various sizes, and to create an artificial recipient population. It was calculated that on average $43 \%$ of potential recipients would be found a HLA-A,B, and DR matched, mixed lymphocyte reaction negative donor from a panel of 100000 volunteers. The validity of this prediction when used clinically depends on the potential recipients and donors having a predominantly white background.

EFFECT OF ETHNIC MISMATCHING OF POTENTIAI DONORS AND RECIPIENTS

Both theoretical calculations ${ }^{23}$ and analysis of unrelated donor searches entered into the IMUST study show that if the potential recipient is not white the probability of finding an HLA matched donor from the existing donor registries (which are predominantly white) is less than $10 \%{ }^{16}$ This HLA mismatching between ethnic groups is currently a serious barrier to finding unrelated donors for non- 
white patients. As discussed above, an extended family donor search may be fruitful for these patients. A future aim is to set up donor panels in countries where large numbers of volunteers from appropriate ethnic groups are available.

\section{BONE MARROW DONORS WORLD WIDE}

Van Rood has compiled a directory in collaboration with the major unrelated donor registries called Bone Marrow Donors Worldwide. This book is used by national donor registries to locate potential donors in other countries for patients for whom a donor search has failed locally. This book may help locate donors for patients with unusual HLA types, including non-white patients.

\section{The future of unrelated donor transplantation}

THE IMUST STUDY

The routine method first established for HLA matching of unrelated donor and recipient pairs was to HLA-A and B type donors at the time they volunteered by routine serological techniques. This was followed by HLA class II typing at the time the donor was found to be HLA-A and B identical with a potential recipient. Initially class II typing was done by serology, but more recently analysis of DNA restriction fragment length polymorphisms (RFLP) or DRB, DQA, and DQB genes ${ }^{24}$ has proved to be more versatile and cost effective. By RFLP analysis it is possible to detect HLA class II variants not apparent with serological techniques. Classically the mixed lymphocyte reaction has been used as the final arbiter of whether an unrelated donor is a suitable match for a potential recipient. Experience has shown that this test is cumbersome and technically difficult to interpret as part of an unrelated donor search. It may be possible to improve matching by replacing the mixed lymphocyte reaction with RFLP typing of class II region genes supplemented where necessary with typing with allele specific oligonucleotide probes ${ }^{25}$ and isoelectric focusing of HLA class I variants not detectable by serological techniques. ${ }^{26}$ These developments would firstly improve the accuracy of HLA typing and secondly speed up the unrelated donor search by eliminating the mixed lymphocyte reaction.

\section{The future of unrelated donor transplantation THE IMUST STUDY}

At present there are no universally accepted guidelines to establish the minimum level of HLA matching required between unrelated donors and their recipients, or clinical guidelines for determining which patients should be considered for UD-BMT. Currently the unrelated donor search and the success of UDBMT is being prospectively evaluated by the IMUST study group. 9 The main conclusions from this study should be available by 1993 . In parallel to the IMUST study, a series of laboratory techniques for HLA typing and matching unrelated donors are being investigated.
UMBILICAL CORD BLOOD TRANSPLANTS

Two problems already clearly defined in UD-BMT are the excessive time taken to find a 'matched' unrelated donor ${ }^{17}$ and the high incidence of acute graft versus host disease seen after UD-BMT. ${ }^{21}$ Recently Gluckman et al reported a successful transplant for Fanconi's anaemia using HLA identical sibling cord blood as the source of haemopoietic progenitors. ${ }^{27}$ The number of haemopoietic progenitor cells measured by short term clonogenic assays for granulocyte-monocyte, erythroid, and mixed colony forming units in a single cord blood donation is only slightly lower than the number routinely infused into adult ID-BMT recipients. ${ }^{28}$ In the future it may be possible to use a bank of cord blood to solve the logistic problems of unrelated donor searches. Furthermore, there is a theoretical possibility that the fetal lymphocytes present in cord blood donations will have less potential for causing graft versus host disease than adult lymphocytes from marrow donors. This alternative source of haemopoietic progenitor cells is being investigated.

1 Locasciulli A, Van't Veer L, Bacigalupo A, et al. Treatment with marrow transplantation or immunosuppression of childhood acquired severe aplastic anaemia: a report for the EBMT Working Party on SAA. Bone Marrow Transplant 1990;6:219-23.

2 Fischer A, Griscelli C, Friendrich W, et al. Bone marrow transplantation for immunoficiencies and osteopetrosis: European survey, 1968-1985. Lancet 1986;ii:1080-4.

3 Goldman JM, Gale RP, Horowitz MM, et al. Bone marrow transplantation for chronic myelogenous leukemia in chronic phase: increased risk of relapse associated with T-cell depletion. Ann Intern Med 1988;108:806-14.

4 Gale RP, Butterini A. Acute lymphoblastic leukemia: chemotherapy versus transplantation. In: Gale RP, Champion RE, eds. Bone marrow transplantation: current controversies. University of California (Los Angeles)
posium. New York: Alan R Liss, 1989:67-74.

5 Lucarelli G, Galimberti M, Polchi P, et al. Bone marrow transplantation in patients with thalassemia. $N$ Engl $\mathcal{Y}$ Med transplantation in

6 Santos GW, Tutschka PJ, Brookmeyer, et al. Marrow transplantation for acute nonlymphoblastic leukemia after treatment with busulfan and cyclophosphamide. $N$ Engl f Med 1983;309:1347-53.

7 Saunders JE, Pritchard S, Mahoney P, et al. Growth and development following marrow transplantation for leukemia. Blood 1986;68:1129-35.

8 Camitta BM, Thomas ED, Nathan DG, et al. A prospective study of androgens and bone marrow transplantation for severe aplastic anemia. Blood 1979;53:504-14.

9 Bradley BA, Gore SM, Howard MR, Hows JM. International Marrow Unrelated Search and Transplant (IMUST) Study. Bone Marrow Transplant 1989;4(suppl 2):44.

10 Beatty PG, Clift RA, Michelson EM, et al. Marrow transplantation from donors other than HLA identical siblings. $N$ Engl f Med 1985;313:765-71.

11 Anasetti C, Amos D, Beatty PG, et al. Effect of HLA compatibility on engraftment of bone marrow transplants in patients with leukemia or lymphoma. $N$ Engl $\mathcal{Y}$ Med in patients with leuki

12 Bacigalupo A, Hows J, Gordon-Smith EC, et al. Bone marrow transplantation for severe aplastic anemia from marrow transplantation for severe aplastic anemia from donors other than HLA ident
Transplant 1988;3:599-607.

13 Beatty PG, Bartolomeo P, Storb R, et al. Treatment of aplastic anemia with marrow grafts from related donors other than HLA genotypically matched siblings. Clinical Transplantation 1987;1:117-23.

14 Camitta BM, Ash R, Menitove K, et al. Bone marrow transplantation for children with severe aplastic anemia: use of donors other than HLA identical siblings. Blood 1989;74: 1852-7.

15 James DCO. Organization of a hospital bone marrow panel. In: Smit Sibinga CT, Das PC, Opelz G, eds. Transplantation and blood transfusion. Symposium on blood transfusion, Groningen, The Netherlands 1983. The Netherlands: M Nijhoff, 1984:131-9.

16 Howard MR, Bradley BA, Gore SM, et al. Predicting the outcome of unrelated marrow donor (UD) searches: a preliminary IMUST study report. Blood 1990;76:546.

17 Ruutu T, Goldman JM. A Nordic registry for volunteer marrow donors? Bone Marrow Transplant 1990;5:273-9.

18 Howard MR, Gore SM, Hows JM, et al. Unrelated donor marrow transplantation between 1977 and 1987 at four marrow transplantation between 1977 and 1987 at four
United Kingdom centres. Transplantation 1990;49:547-53.

19 Trigg ME, Gingrick R, Goekin N, et al Low rejection when using unrelated or haploidentical donors for children 
with leukaemia undergoing marrow transplantation. Bone Marrow Transplant 1989;4:431-7.

20 Marsh JCW, Hows JM, Bryett KA, Gordon-Smith EC Young age and outcome of treatment with antilymphocyte globulin for aplastic anaemia. Bone Marrow Transplan 1988;3(suppl 1):238

21 Ash RC, Casper JT, Chitamber CR, et al. Successful allogeneic transplantation of $T$ depleted bone marrow from closely HLA matched unrelated donors. $N$ Engl f Med 1990;322:485-94.

22 Bradley BA, Gilkes R, Gore SM, Klouda P. How many HLA typed volunteer donors for bone marrow transplantation (BMT) are needed to provide an efficient service? Bome Marrow Transplant 1987;2(suppl 1):79.

23 Sonnenberg FA, Eckman MH, Pautier SG. Bone marrow donor registries: the relation between registry size and probability of finding complete and partial matches. Blood probability of fin

24 Bidwell JL, Bidwell EA, Savage DA, et al. A DNA-RFLP typing system that positively identifies serologically well defined and ill defined HLA DR and DQ alleles, including DRw10. Transplantation 1988;45:640-6.

25 Tiercy JM, Zwahlen F, Betuel H, et al. Improved HLA class II matching in bone marrow transplantation with unrelated donors by DNA oligonucleotide probing. Exp Hemato 1989;17:705.

26 Neefjes JJ, Breur-Vriesendorp BS, Seventer GA, et al. A improved biochemical method for the analysis of HLA class I antigens: definition of new HLA Class I subtypes. Hum Immunol 1986;16:169-81.

27 Gluckman E, Broxmeyer HE, Auerbach AD, et al. Hematopoietic reconstitution in a patient with Fanconi's anemia by means of umbilical cord blood from a HLA identical sibling. N Engl f Med 1989;321:1174-8.

28 Broxmeyer HE, Douglas GW, Hangoc G, et al. Human umbilical cord blood as a potential source of transplantable hemopoietic stem/progenitor cells. Proc Natl Acad Sci USA hemopoietic stem

Breast milk and necrotising enterocolitis

Breast milk protects babies against necrotising enterocolitis. 'I know that', I hear you say. And on what basis do you know that? On the basis of a few inconclusive clinical observations and animal models according to workers at the MRC Dunn Nutrition Unit in Cambridge.

The Cambridge based five centre trial of feeding of low birthweight babies $(<1850 \mathrm{~g})$ came up with remarkable results in June 1990 showing that babies fed a preterm formula developed better than those fed on standard formula (see Archivist, November 1990:1265). Now (Lancet 1990;336:1519-23) they have shown that breast milk has a considerable protective effect against necrotising enterocolitis.

The disease was 6-10 times more common in babies fed exclusively on formula milk than in those given only human milk. It made no difference whether the human milk was fresh mothers' milk or pasteurised donor milk or whether the formula milk was standard or preterm. The benefits of breast feeding have usually been said to be eliminated if complementary formula feeds are given but in this trial babies fed exclusively on formula were three times as likely to get necrotising enterocolitis as those fed on both human and formula milks. Delaying the first feed reduced the incidence of the disease in formula fed babies but not in those given human milk. With increasing gestational age above 28 weeks babies fed formula had a persistently high incidence of necrotising enterocolitis (8-9\%) whereas in those given human milk the incidence fell progressively and there were no cases at gestations above 33 weeks. The authors calculate that giving human milk to all low birthweight babies could prevent about 500 cases of necrotising enterocolitis and 100 deaths each year in the United Kingdom.

Human milk is good for premature babies. Preterm formula is good for premature babies. The suggestion is that you can have the best of both worlds by using both. 